\title{
Prognostic factor for Korean patients with renal cell carcinoma and venous tumor thrombus extension: application of the new 2009 TNM staging system
}

\author{
Min Chul Cho, Jung Kwon Kim, Kyung Chul Moon, Hyeon Hoe Kim, Cheol Kwak \\ Department of Urology, Dongguk University (MCC); Department of Urology (JKK, HHK, CK), College \\ of Medicine, Seoul, Korea and Department of Pathology (KCM), Seoul National University College of \\ Medicine, Seoul, Korea
}

\section{ABSTRACT}

Purpose: To study the surgical outcomes of radical nephrectomy with thrombectomy and to determine prognostic factors for survival of Korean patients with renal cell carcinoma (RCC) and venous tumor thrombus.

Materials and Methods: A total of 124 patients with RCC and venous tumor thrombus who underwent radical nephrectomy and thrombectomy were included in this retrospective study. Cancer-specific survival (CSS) and recurrence-free survival (RFS) rates were analyzed retrospectively according to various prognostic factors.

Results: The median overall follow-up period for all patients was 29.0 months; the median survival period was 50.0 months. The 2-, 5- and 10-year CSS rates for all patients were 64.2\%, 47.1\% and 31.7\%, respectively. Those for 76 patients (pNo/xM0) without metastasis at presentation were $80.9 \%, 64.5 \%$ and $44.9 \%$, respectively. For all patients, lower body mass index (BMI), higher Fuhrman grade, presence of symptoms, perinephric fat invasion, invasion of inferior vena cava (IVC) wall, lymph node (LN) involvement and distant metastasis at presentation were independent predictors for decreased CSS on multivariate analysis, while thrombus level was not. For non-metastatic patients, lower BMI, presence of symptoms and tumor size were independently associated with decreased CSS. In terms of RFS, lower BMI, presence of perinephric fat invasion were prognostic factors for recurrence.

Conclusions: Our data suggest that obesity is independently associated with better survival or lower risk of tumor recurrence in Korean patients undergoing radical nephrectomy with tumor thrombectomy. Also, our results indicate that Fuhrman grade, presence of symptoms, perinephric fat invasion and invasion of IVC wall, LN involvement and distant metastasis at presentation are independent predictors for survival.

\section{ARTICLE INFO}

\section{Key words:}

Carcinoma; Carcinoma, Renal Cell; Thrombectomy; Body Mass Index

Int Braz J Urol. 2013; 39: 353-63

Submitted for publication: September 09, 2012

Accepted after revision: April 02, 2013

\section{INTRODUCTION}

About 5-10\% of renal cell carcinoma (RCC) extends as tumor thrombus into the venous system such as renal vein or inferior vena cava (1). Despite advances in radiation, chemotherapy, and immunotherapy, surgical resection is still the standard treatment for RCC with tumor thrombus (2). However, the range of 5-year survival rates for RCC patients with venous tumor thrombus treated with radical nephrectomy and tumor thrombectomy is only 35\% - 45\% despite the developments 
in surgical techniques and perioperative care (35). Furthermore, even the 5-year survival rate for patients without evidence of nodal or distant metastasis at presentation is just 45\%-65\% (4,6-8).

Although the prognostic significance of many factors has been tested, only a few are widely used in clinical practice (9). Currently, pathologic stage (T stage), lymph node (LN) status ( $\mathrm{N}$ stage), and histologic grade represent the main prognostic variables in patients with RCC (10). Accordingly, the American Joint Committee on Cancer (AJCC) TNM classification is regularly revised and a new 2009 AJCC TNM stage classification system has been recently proposed (11).

It has been demonstrated that RCC has different clinical characteristics according to ethnicity, the presenting symptoms, course of disease, and outcomes after standard treatment varied significantly between patients of Caucasian, Hispanic, African-American, and Asian backgrounds (12). To date, there has been sparse data on surgical outcomes and prognostic factors of survival after radical nephrectomy and thrombectomy in Asian populations with RCC and venous tumor thrombus since most studies have been performed in Western countries. The aim of this study was to examine the surgical outcomes of radical nephrectomy with thrombectomy. We also evaluated the prognostic factors that influence survival of Korean patients with RCC and tumor thrombus extension into renal vein or inferior vena cava (IVC), with application of the newly revised 2009 AJCC TNM staging system.

\section{MATERIALS AND METHODS}

\section{Study design}

This study was approved by the Institutional Review Board of our institution. From February 1988 to April 2009, 1457 patients underwent nephrectomy for RCC at our institution. Among these, a total of 124 patients who underwent radical nephrectomy and thrombectomy for RCC and venous tumor thrombus were included in this retrospective study. The exclusion criteria included the presence of von Hippel-Lindau disease, tuberous sclerosis syndrome, and synchronous bilateral tumor. Pathologic slides from all specimens were re-reviewed by a sin- gle uropathologist (KCM) who had no knowledge of patient outcomes.

A retrospective review was performed to evaluate patient demographics, presence or absence of clinical symptoms at initial presentation, laboratory findings, American Society of Anesthesiologists (ASA) scores, TNM stage, tumor size, laterality, perioperative complications, and pathologic features. Pathologic staging was determined according to the newly revised 2009 AJCC TNM classification system (11). Tumor grade and histological classification were determined according to Fuhrman's nuclear grading system and 2004 WHO classification system, respectively. Body mass index (BMI) was categorized according to the cutoff points for Asian populations recommended by the WHO (normal; < $23 \mathrm{~kg} / \mathrm{m}^{2}$, overweight; $23-25 \mathrm{~kg} / \mathrm{m}^{2}$, obese; $\geq 25 \mathrm{~kg} /$ $\mathrm{m}^{2}$ ) (13). Preoperative evaluation included medical history, physical examination, routine laboratory work, chest $\mathrm{x}$-ray, computed tomography (CT) of the abdomen and pelvis, and selective use of chest $\mathrm{CT}$ and bone scanning. Postoperative follow-up included blood tests, chest x-ray, and abdominal CT. Chest CT, brain MRI, and bone scan were performed as recommended.

\section{Surgical technique}

All patients underwent radical nephrectomy and thrombectomy through a flank, Chevron and thoracoabdominal approach. In one patient with right atrial thrombus, median sternotomy was performed to assess the right atrium. The venous tumor thrombus was removed according to its extent. Liver mobilization was performed in three patients with infrahepatic IVC thrombus, five with retrohepatic IVC thrombus and two with supradiaphragmatic IVC thrombus. A cardiopulmonary bypass was required for three of five patients with retrohepatic IVC thrombus and two with supradiaphragmatic IVC thrombus. An IVC filter was placed in three patients with IVC thrombus. In nine (7.3\%) patients in whom invasion of the IVC wall was observed, the wall was partially resected with a negative margin and reconstructed with synthetic grafts as appropriate.

\section{Data analysis}

The statistical endpoints in our analysis were cancer-specific survival (CSS) and recurrence- 
-free survival (RFS) of the patients. Patients with evidence of metastases at presentation were excluded from analysis of RFS. Survival analyses were performed according to the Kaplan-Meier method. Cox proportional hazard regression model was used to evaluate the prognostic factors for outcomes and their hazard ratio (HR). Variables with p-values less than 0.05 in the univariate analysis were included in the multivariate model and their HR with a 95\% confidence interval (CI) was calculated. A 5\% level of significance was used for all analyses and all statistical tests were two-sided. The Statistical Package for the Social Sciences (version 17.0) was used for analysis.

\section{RESULTS}

\section{General characteristics}

Baseline clinicopathological and tumor characteristics of the patients are summarized in Table-1. The median follow-up period for all patients was 29.0 months (range, 1 to 222), while that for survivors at the last follow-up was 49.0 months (range 1 to 222). At the time of analysis, 65 patients (52.4 \%) died of RCC at a median follow-up period of 14.0 months (range 3 to 134), 2 patients $(1.6 \%)$ died of non-cancer-related causes at 76 and 111 months postoperatively, respectively, 21 patients $(16.9 \%)$ survived with the disease, and 36 patients (29.0\%) were alive with no evidence of disease.

In two patients with left-sided RCC involving retrohepatic or infrahepatic IVC, a pulmonary embolism occurred intraoperatively. One of the patients died 1 day after operation, and overall perioperative mortality (death within one month after surgery) was $0.8 \%$.

\section{Survival, recurrence, and prognostic factors}

The 2-, 5- and 10-year CSS rates for all patients were $64.2 \%, 47.1 \%$ and $31.7 \%$, respectively. The median CSS time was 50.0 months for all patients. For 48 patients with metastasis (N1 or M1) at presentation, the 2-, and 5-year CSS rates were $35.9 \%$ and $16.9 \%$, respectively, while the median CSS time was 16 months (Figure-1). For all patients as well as patients (pNo/xMO) without metastasis at presentation, the CSS rates in the patients with renal vein thrombus were higher than those in the pa- tients with IVC thrombus (Figure-1). For 76 patients (No/xM0) without metastasis at presentation, the 2-, 5-, and 10-year CSS rates were 80.9\%, 64.5\% and $44.9 \%$, respectively, and the median survival time was 107.0 months (Figure-1). The 2- and 5-year RFS were 50.7\% and 37.3\%, respectively, and the median RFS time was 25 months. Tumors recurred in 49 (64.5\%) of the patients without metastasis at presentation; 28 of these individuals developed isolated metastases and 21 had disease recurrences at multiple sites. Median time for recurrence was 12 months (range, 1 to 222). Lung was the most common site of first recurrence (39.5\%) followed by liver (14.5\%), bone (13.2\%), and brain (6.8\%). Of the 30 patients with lung metastases, 15 developed isolated lung metastases and 15 had metastases in multiple sites.

Multivariate Cox regression analysis showed that lower BMI, presence of symptoms at presentation, higher Fuhrman grade, LN involvement, distant metastasis at presentation, perinephric fat invasion and invasion of IVC wall were independent factors for predicting cancer-specific death in all patients (Table-2). Tumor thrombus level (IVC versus renal vein) was significantly associated with cancer-specific death in the univariate model (Figure-1), but not an independent predictor in the multivariate analysis (Table-2).

For the 76 patients without metastasis at presentation, multivariate model showed that lower BMI, the presence of symptoms at presentation and tumor size correlated independently with reduced CSS rates (Table-3). In terms of RFS, lower BMI and the presence of perinephric fat invasion were the independent prognostic factors for relapse in the multivariate model (Table-3).

\section{DISCUSSION}

To date, reports on survival rates and prognostic factors for CSS and RFS after radical nephrectomy and thrombectomy in Asian populations with RCC and venous tumor thrombus have been limited to a small number of series $(14,15)$. Although performed in Western country, a recent study involving a large population based on the California Cancer Registry showed that Asian/Pacific Islanders have a higher survival rate than all other racial and ethnic groups (12). In our study, 
Table 1 - Baseline clinical and pathological characteristics on 124 patients.

\begin{tabular}{|c|c|c|}
\hline \multirow[t]{2}{*}{ Variables } & \multicolumn{2}{|c|}{ No. pts $(\%)$ or Mean \pm SD } \\
\hline & $\begin{array}{l}\text { Renal vein thrombus } \\
\qquad(\mathrm{n}=88)\end{array}$ & $\begin{array}{l}\text { IVC thrombus } \\
\qquad(n=36)\end{array}$ \\
\hline \multicolumn{3}{|l|}{ Clinical variables } \\
\hline Age, yr & $57.0 \pm 11.2$ & $55.5 \pm 11.6$ \\
\hline $\mathrm{BMI}, \mathrm{kg} / \mathrm{m}^{2}$ & $23.3 \pm 2.6$ & $23.3 \pm 3.4$ \\
\hline$<23$ & $37(42.0)$ & $19(52.8 \%)$ \\
\hline 23 - 25 (overweight) & $26(29.6)$ & $7(19.4 \%)$ \\
\hline$\geq 25$ (obese) & $25(28.4)$ & $10(27.8 \%)$ \\
\hline No. sex (M/F) & $60(68.2)$ / $28(31.8)$ & $25(69.4) / 11(30.6)$ \\
\hline \multicolumn{3}{|l|}{ No. ASA score } \\
\hline 1 & $29(33.0)$ & $7(19.4)$ \\
\hline 2 & $46(52.3)$ & $21(58.3)$ \\
\hline 3 & $13(14.7)$ & $6(16.7)$ \\
\hline 4 & $0(0.0)$ & $2(5.6)$ \\
\hline No. symptoms (\%) & $60(68.2)$ & $30(83.3)$ \\
\hline Gross hematuria & $26(29.5)$ & $12(33.3)$ \\
\hline Pain/discomfort & $25(28.4)$ & $12(33.3)$ \\
\hline Palpable mass & $2(2.3)$ & $4(11.1)$ \\
\hline Weight loss & $6(6.8)$ & $3(8.3)$ \\
\hline Others & $6(6.8)$ & $3(8.3)$ \\
\hline No. preop. renal insufficiency $(\%)^{*}$ & $23(26.1)$ & $13(36.1)$ \\
\hline \multicolumn{3}{|l|}{ Pathological variables } \\
\hline Laterality (Rt/Lt) & $24(27.3) / 64(72.7)$ & $27(75.0) / 9(25.0)$ \\
\hline T classification $(3 a / 3 b / 3 c / 4)$ & $84(95.5) / 0(0.0) / 0(0.0) / 4(4.5)$ & $0(0.0) / 26(72.2) / 8(22.2) / 2(5.6)$ \\
\hline N classification (N0 or Nx / N1) & 69 (80.7) / 17 (19.3) & $25(75.0) / 9(25.0)$ \\
\hline M classification (M0 / M1) & $64(72.7)$ / 24 (27.3) & $22(61.1) / 14(38.9)$ \\
\hline
\end{tabular}




\section{Fuhrman grade}

G1 / G2
G3 / G4

Thrombus level

Renal vein only

Subdiaphragmatic IVC

Supradiaphragmatic IVC

No. perinephric fat invasion (\%)

No. adrenal gland invasion (\%)

No. collecting system invasion (\%)

No. renal hilar invasion

No. lymphovascular invasion (\%)

No. sarcomatoid feature (\%)†

No. gross necrosis (\%)‡

No. invasion of renal vein wall (\%)

No. invasion of IVC wall (\%)

\section{No. histological type}

Clear cell

Papillary

Chromophobe

Collecting ducts of Bellini

Xp11.2 translocation

Unclassified
$2(2.3) / 18(20.5)$

$46(52.2) / 22(25)$

$88(100.0)$

$0(0.0)$

$0(0.0)$

$43(48.9)$

$4(4.5)$

$31(35.2)$

$23(27.4 \%)$

$10(11.4)$

$8(9.1)$

$59(70.2)$

24 (27.3)

$0(0.0)$

78 (88.6)

$3(3.4)$

$4(4.5)$

$0(0.0)$

$2(2.3)$

$1(1.1)$

$9.4 \pm 3.3$
$0(0.0) / 5(13.9)$

$22(61.1) / 9(25.0)$
$0(0.0)$

$34(94.4)$

17 (47.2)

$1(2.8)$

17 (47.2)

$13(38.2 \%)$

$10(27.8)$

$3(8.3)$

$20(58.8)$

$10(27.8)$

$9(25.0)$

$24(66.7)$

$6(16.7)$

$2(5.6)$

$2(5.6)$

$1(2.8)$

$1(2.8)$

$10.1 \pm 3.8$

Tumor size, cm

BMI = body mass index; $\mathbf{A S A}$ score = American Society of Anesthesiologists score; $\mathbf{I V C}=$ inferior vena cava; $\mathbf{M D R D}$ GFR = Modification of Diet in Renal Disease glomerular filtration rate (calculated using the abbreviated MDRD study equation)

* Renal insufficiency: preoperative MDRD GFR less than $60 \mathrm{ml}$ per minute per $1.73 \mathrm{~m} 2$, MDRD GFR = Modification of Diet in Renal Disease glomerular filtration rate (calculated using the abbreviated MDRD study equation) † Sarcomatoid feature: a spindle cell malignancy that had the histological appearance of a sarcoma $\ddagger$ Gross necrosis: the presence of necrosis in the gross specimen according to the pathology reports 
Figure 1 - Estimated cancer-specific survival (CSS) using Kaplan-Meier curve according to (a) thrombus level (renal vein vs. IVC) in overall patients; (b) presence or absence of metastasis (pN0/xMO vs. pN1 or M1) in overall patients; (c) thrombus level (renal vein vs. IVC) in non-metastatic (pNO/xMO) patients; (d) presence or absence of metastasis (pNO/xMO vs. pN1 or M1) in patients with renal vein thrombus only; (e) presence or absence of metastasis (pNO/xMO vs. pN1 or M1) in patients with IVC thrombus. IVC = inferior vena cava.
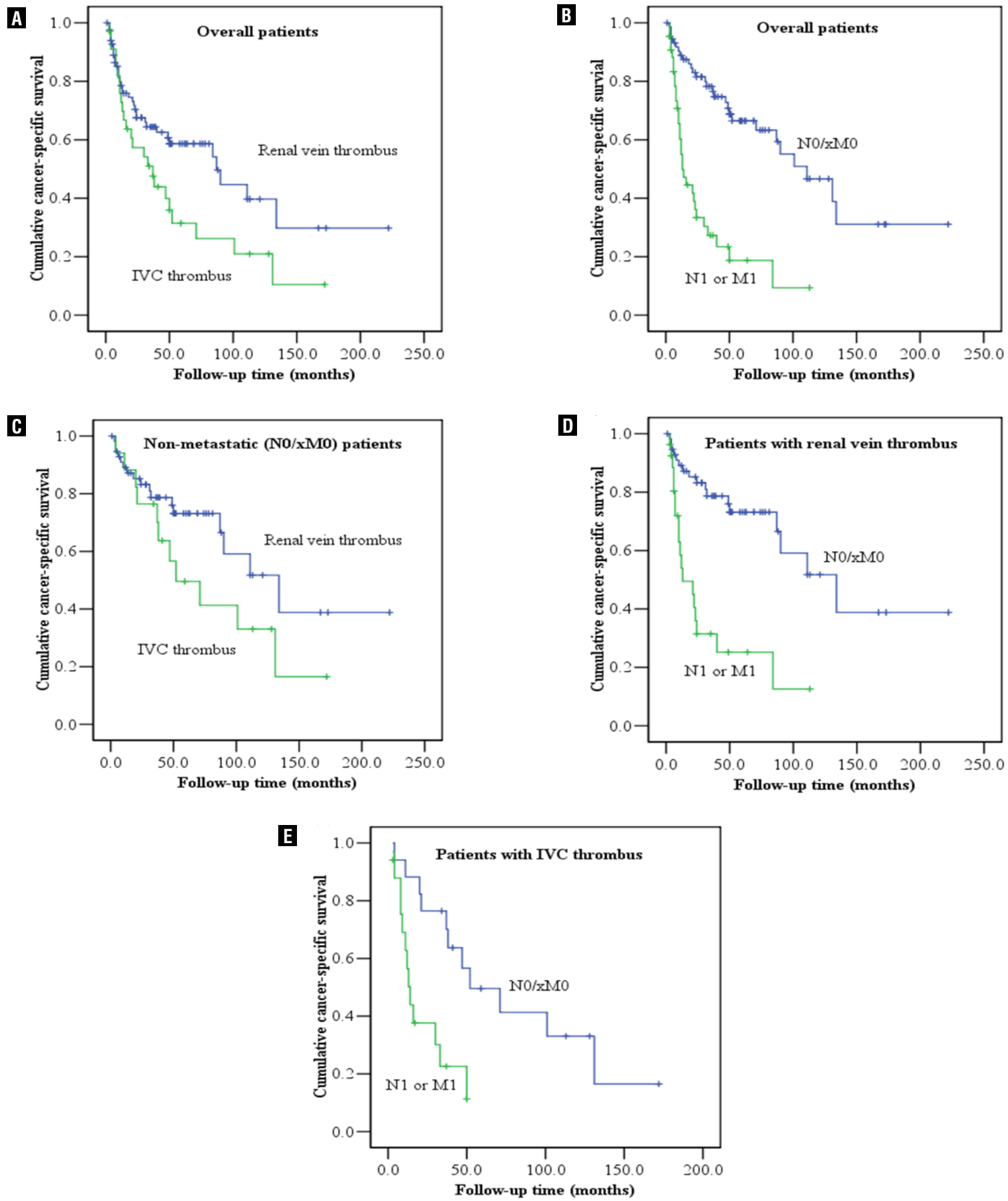
Table 2 - Multivariate Cox proportional hazard analysis for cancer-specific death in all patients.

\begin{tabular}{|c|c|c|c|}
\hline Covariates & Hazard ratio & $95 \% \mathrm{Cl}$ & $\mathrm{p}$-value \\
\hline \multicolumn{4}{|l|}{ BMI } \\
\hline$<23 \mathrm{~kg} / \mathrm{m}^{2}$ & 1.000 & & \\
\hline $23-25 \mathrm{~kg} / \mathrm{m}^{2}$ & 0.768 & $0.356-1.658$ & 0.502 \\
\hline$\geq 25 \mathrm{~kg} / \mathrm{m}^{2}$ & 0.237 & $0.105-0.535$ & 0.001 \\
\hline \multicolumn{4}{|l|}{ ASA score } \\
\hline $1-2$ & 1.000 & & \\
\hline $3-4$ & 1.949 & $0.863-4.398$ & 0.108 \\
\hline Presence of clinical symptoms at presentation & 3.376 & $1.239-9.195$ & 0.017 \\
\hline \multicolumn{4}{|l|}{ Tumor thrombus level } \\
\hline Renal vein thrombus & 1.000 & & \\
\hline IVC thrombus & 1.241 & $0.580-1.908$ & 0.573 \\
\hline LN metastasis & 2.143 & $1.010-4.786$ & 0.047 \\
\hline Distant metastasis & 3.802 & $1.803-8.017$ & $<0.001$ \\
\hline Tumor size & 1.050 & $0.951-1.160$ & 0.334 \\
\hline \multicolumn{4}{|l|}{ Fuhrman grade } \\
\hline G1-2 & 1.000 & & \\
\hline G3-4 & 5.340 & $1.455-19.593$ & 0.012 \\
\hline Presence of perinephric fat invasion & 2.147 & $1.023-4.508$ & 0.043 \\
\hline Presence of sarcomatoid change & 1.341 & $0.429-4.190$ & 0.613 \\
\hline Presence of collecting system invasion & 1.245 & $0.598-2.590$ & 0.558 \\
\hline Presence of IVC wall invasion & 4.496 & $1.291-15.657$ & 0.018 \\
\hline
\end{tabular}

BMI = body mass index; ASA score = American Society of Anesthesiologists score; IVC = inferior vena cava; $\mathbf{L N}=$ lymph node

* This table listed only the statistically significant prognostic factors for each outcome in the univariate Cox proportional hazard analysis.

the 2-, 5-, and 10-year CSS rates of RCC patients with tumor thrombus extension into the renal vein only and those with IVC extension were 68.5\%, $55.3 \%$, and $36.4 \%$, and $54.2 \%, 29.4 \%$, and $19.6 \%$, respectively. Similar to our results, previous studies of Asian population have reported 5-year CSS rates between 30\% 40\% in patients with RCC involving the IVC $(14,15)$. In our study, the 2-, 5and, 10-year CSS rates of all patients and those with non-metastatic RCC were $64.2 \%, 47.1 \%$ and $31.7 \%$, and $80.9 \%, 64.5 \%$ and $44.9 \%$, respectively. These rates appear to be a little higher than those of most reports from Western countries $(3-5,7,8,16)$. However, our patient population included a higher 
Table 3 - Multivariate Cox proportional hazard analysis for cancer-specific death and recurrence in non-metastatic RCC (pNO/XMO) patients.

\begin{tabular}{|c|c|c|c|}
\hline Covariates* & Hazard ratio & $95 \% \mathrm{Cl}$ & $\mathrm{p}$-value \\
\hline \multicolumn{4}{|l|}{ Cancer-specific death } \\
\hline \multicolumn{4}{|l|}{ BMI } \\
\hline$<23 \mathrm{~kg} / \mathrm{m}^{2}$ & 1.000 & & \\
\hline $23-25 \mathrm{~kg} / \mathrm{m}^{2}$ & 0.305 & $0.111-0.840$ & 0.022 \\
\hline$\geq 25 \mathrm{~kg} / \mathrm{m}^{2}$ & 0.184 & $0.063-0.534$ & 0.002 \\
\hline Presence of clinical symptoms at presentation & 5.182 & $1.199-22.391$ & 0.028 \\
\hline \multicolumn{4}{|l|}{ Tumor thrombus level } \\
\hline Renal vein thrombus & 1.000 & & \\
\hline IVC thrombus & 2.179 & $0.975-4.873$ & 0.058 \\
\hline Tumor size & 1.113 & $1.012-1.224$ & 0.027 \\
\hline \multicolumn{4}{|l|}{ Recurrence } \\
\hline \multicolumn{4}{|l|}{ BMI } \\
\hline$<23 \mathrm{~kg} / \mathrm{m}^{2}$ & 1.000 & & \\
\hline $23-25 \mathrm{~kg} / \mathrm{m}^{2}$ & 0.440 & $0.210-0.922$ & 0.030 \\
\hline$\geq 25 \mathrm{~kg} / \mathrm{m}^{2}$ & 0.406 & $0.195-0.846$ & 0.016 \\
\hline Tumor size & 1.080 & $0.995-1.173$ & 0.066 \\
\hline Presence of perinephric fat invasion & 1.866 & $1.002-3.484$ & 0.048 \\
\hline
\end{tabular}

BMI = body mass index; ASA score $=$ American Society of Anesthesiologists score

* This table listed only the statistically significant prognostic factors for each outcome in the univariate Cox proportional hazard analysis.

proportion of individuals with tumor thrombus extension into renal vein only than other studies except for the one by Wagner et al., and may explain these seemingly higher survival rates (16).

One of the significant findings of our study was that obesity was independently associated with better survival or lower risk of tumor recurrence in Korean patients with RCC and venous tumor thrombus. There has been a controversy about a prognostic impact of BMI on survival of patients with RCC (17-19). Recently, we demonstrated that overweight or obese Korean patients with RCC have more favorable pathological fea- tures and a better prognosis than those with normal BMI, which is in accordance with the result from a study by Awakura et al. evaluating Japanese patients with RCC $(20,21)$. To our knowledge, our study is the first to demonstrate the prognostic impact of obesity on survival and tumor recurrence after radical nephrectomy with thrombectomy for treating RCC and venous tumor thrombus. In our study, there was no difference in clinical or histopathological features between obese patients and those with normal BMI (data not shown). However, the underlying mechanisms for the effect of BMI on RCC survival and prognosis remain to 
be elucidated. It has been suggested adipose tissue in obese patients secretes certain proteins and signaling factors including leptin and adiponectin, some of which could be involved in suppressing RCC progression $(21,22)$. Also, lower BMI related to the presence of cachexia might be a possible explanation.

Another significant finding of our study was that a higher Fuhrman grade was independently associated with worse prognosis in Korean patients with RCC and venous tumor thrombus. Fuhrman grade is currently the most widely used grading protocol in North America and Europe, and higher grades are correlated with tumor aggressiveness and increased metastatic potential $(23,24)$. The prognostic significance of histological grade in patients with RCC and venous tumor thrombus is controversial $(4,6-8,16,25)$. In our study, Fuhrrnan grade was found to be one of most important prognostic factors for survival and relapse in patients with RCC and venous tumor thrombus, supporting the role of histological grade as an important predictor of patient outcomes. This is in accordance with a previous report from Japan demonstrating that tumor grade has more potential prognostic significance compared to other factors (14). Thus, tumor aggressiveness characterized by histological grade as well as the presence of local extension or distant metastasis of tumor may have important prognostic significance as in Asian populations with RCC and venous tumor thrombus (14).

Advanced disease at presentation is another unfavorable prognostic factor in patients with RCC, as confirmed by most studies $(4,7,8,16)$. In accordance with previous Western studies including a recent study by Martínez-Salamanca et al. that evaluated the newly revised 2009 TNM staging system, this study demonstrated that the presence of LN involvement and distant metastasis at presentation were independent predicting factors for survival in Korean patients with RCC and venous tumor thrombus $(4,7,8,16)$.

The newly revised 2009 AJCC TNM staging system stratifies the pT3b group according to tumor thrombus extension (11). However, our study failed to demonstrate any difference in survival between patients with tumor thrombus ex- tension into the renal vein only and those with IVC extension. This result could have been due to the relatively small size of the group with IVC extension. Furthermore, the presence of invasion of IVC wall, not the level of tumor thrombus, was found to be a significant prognostic factor of survival in several studies (26-28). Thus, invasion of IVC wall by tumor thrombus rather than thrombus level may predict a poor prognosis. In accordance with these facts, our study showed that the presence of invasion of IVC wall was an independent prognostic factor of survival in Korean patients with RCC and venous tumor thrombus.

The presence or absence of symptoms at presentation has been shown to have prognostic significance in patients with RCC $(29,30)$. Thus, the presence of clinical symptoms at presentation may be related to more aggressive tumors and associated with worse clinical outcomes. However, there are limited data on the influence of the presence of symptoms at presentation on survival of patients with RCC and venous tumor thrombus. Our study suggested that the presence of clinical symptoms at presentation was an independent predicting factor of cancer-specific death in both all and non-metastatic RCC patients. Contrary to our result, multivariate analysis in two studies from Western countries failed to demonstrate prognostic significance of the presence of symptoms at presentation in RCC patients with venous tumor thrombus $(4,16)$.

Interestingly, intraoperative pulmonary embolisms only developed in two patients with left-sided RCC involving IVC who did not undergo preoperative placement of an IVC filter. This may be due to the presence of a longer venous tumor thrombus caused by a longer left renal vein in left-sided RCC patients compared to that in right-sided RCC cases, resulting in a higher probability of fractured thrombus producing pulmonary embolisms. Thus, preoperative placement of an IVC filter might be needed in patients with left-sided RCC involving IVC.

Some potential shortcomings of our study warrant consideration. Our study is limited by both its retrospective nature and the fact that it was conducted at a single institution. Nevertheless, our study involved the largest group 
of Asian patients with RCC and venous tumor thrombus extension.

\section{CONCLUSIONS}

Our study indicates that CSS rate after radical nephrectomy with tumor thrombectomy for Korean patients with RCC and venous tumor thrombus is not lower than that reported in Western populations. Our data suggest that obesity is independently associated with better survival or lower risk of tumor recurrence in Korean patients undergoing radical nephrectomy with tumor thrombectomy to treat RCC with venous tumor thrombus. In addition, Fuhrman grade, the presence or absence of symptoms at presentation, LN involvement, distant metastasis at presentation, perinephric fat invasion and invasion of IVC wall were found to be independent prognostic factors for survival after surgery, while tumor thrombus level (renal vein versus IVC) was not. However, additional studies with larger cohorts including prospective, multicenter, comparative studies among patients of different ethnicities are necessary to fully validate the newly revised 2009 TNM staging in Asian population such as Korean patients with RCC and venous tumor thrombus.

\section{CONFLICT OF INTEREST}

\section{None declared.}

\section{REFERENCES}

1. Rini BI, Campbell SC, Escudier B: Renal cell carcinoma. Lancet. 2009; 373: 1119-32.

2. Wotkowicz C, Wszolek MF, Libertino JÁ: Resection of renal tumors invading the vena cava. Urol Clin North Am. 2008; 35: 657-71.

3. Coons BJ, Stec AA, Stratton KL, Chang SS, Cookson MS, Duke Herrell $S$, et al.: Prognostic factors in T3b renal cell carcinoma. World J Urol. 2009; 27: 75-9.

4. Klatte T, Pantuck AJ, Riggs SB, Kleid MD, Shuch B, Zomorodian N, et al.: Prognostic factors for renal cell carcinoma with tumor thrombus extension. J Urol. 2007; 178: 1189-95; discussion 1195.

5. Lambert EH, Pierorazio PM, Shabsigh A, Olsson CA, Benson MC, McKiernan JM: Prognostic risk stratification and clini- cal outcomes in patients undergoing surgical treatment for renal cell carcinoma with vascular tumor thrombus. Urology. 2007; 69: 1054-8.

6. Blute ML, Leibovich BC, Lohse CM, Cheville JC, Zincke H: The Mayo Clinic experience with surgical management, complications and outcome for patients with renal cell carcinoma and venous tumour thrombus. BJU Int. 2004; 94: 33-41.

7. Haferkamp A, Bastian PJ, Jakobi H, Pritsch M, Pfitzenmaier $J$, Albers $P$, et al.: Renal cell carcinoma with tumor thrombus extension into the vena cava: prospective long-term followup. J Urol. 2007; 177: 1703-8.

8. Martínez-Salamanca JI, Huang WC, Millán I, Bertini R, Bianco FJ, Carballido JA, et al.: Prognostic impact of the 2009 UICC/AJCC TNM staging system for renal cell carcinoma with venous extension. Eur Urol. 2011; 59: 120-7.

9. Moch H, Artibani W, Delahunt B, Ficarra V, Knuechel R, Montorsi F, et al.: Reassessing the current UICC/AJCC TNM staging for renal cell carcinoma. Eur Urol. 2009; 56: 636-43.

10. Volpe A, Patard JJ: Prognostic factors in renal cell carcinoma. World J Urol. 2010; 28: 319-27.

11. Edge SB, Byrd DR, Compton CC, Fritz AG, Greene FL, Trotti A: AJCC cancer staging manual, 7th ed. Springer, New York, 2010.

12. Stafford HS, Saltzstein SL, Shimasaki S, Sanders C, Downs TM, Sadler GR: Racial/ethnic and gender disparities in renal cell carcinoma incidence and survival. J Urol. 2008; 179: 1704-8.

13. The Asia-Pacific perspective: Redefining obesity and its treatment. Sydney, Australia: Health Communications Australia Pty Limit; 2000. WHO Western Pacific Region, International Association for the study of Obesity (IASO), International Obesity Task Force (IOTF).

14. Terakawa T, Miyake H, Takenaka A, Hara I, Fujisawa M: Clinical outcome of surgical management for patients with renal cell carcinoma involving the inferior vena cava. Int J Urol. 2007; 14: 781-4.

15. Tanaka M, Fujimoto K, Okajima E, Tanaka N, Yoshida K, Hirao $\mathrm{Y}$ : Prognostic factors of renal cell carcinoma with extension into inferior vena cava. Int J Urol. 2008; 15: 394-8.

16. Wagner B, Patard JJ, Méjean A, Bensalah K, Verhoest G, Zigeuner $\mathrm{R}$, et al.: Prognostic value of renal vein and inferior vena cava involvement in renal cell carcinoma. Eur Urol. 2009; 55: 452-9.

17. Schips L, Lipsky K, Zigeuner R, Gidaro S, Salfellner M, Rehak $P$, et al.: Does overweight impact on the prognosis of patients with renal cell carcinoma? A single center experience of 683 patients. J Surg Oncol. 2004; 88: 57-61; discussion $61-2$.

18. Donat SM, Salzhauer EW, Mitra N, Yanke BV, Snyder ME, Russo P: Impact of body mass index on survival of patients with surgically treated renal cell carcinoma. J Urol. 2006; 175: 46-52. 
19. Kamat AM, Shock RP, Naya Y, Rosser CJ, Slaton JW, Pisters LL: Prognostic value of body mass index in patients undergoing nephrectomy for localized renal tumors. Urology. 2004; 63: 46-50.

20. Jeon HG, Jeong IG, Lee JH, Lee CJ, Kwak C, Kim HH, et al.: Prognostic value of body mass index in Korean patients with renal cell carcinoma. J Urol. 2010; 183: 448-54.

21. Awakura Y, Nakamura E, Ito N, Yamasaki T, Kamba T, Kamoto $\mathrm{T}$, et al.: Influence of body mass index on prognosis of Japanese patients with renal cell carcinoma. Urology. 2007; 70: $50-4$.

22. Drabkin HA, Gemmill RM: Obesity, cholesterol, and clear-cell renal cell carcinoma (RCC). Adv Cancer Res. 2010; 107: 3956 .

23. Medeiros LJ, Jones EC, Aizawa S, Aldape HC, Cheville JC, Goldstein NS, et al.: Grading of renal cell carcinoma: Workgroup No. 2. Union Internationale Contre le Cancer and the American Joint Committee on Cancer (AJCC). Cancer. 1997; 80: 990-1.

24. Bostwick DG, Murphy GP: Diagnosis and prognosis of renal cell carcinoma: highlights from an international consensus workshop. Semin Urol Oncol. 1998; 16: 46-52.
25. Klaver S, Joniau S, Suy R, Oyen R, Van Poppel H: Analysis of renal cell carcinoma with subdiaphragmatic macroscopic venous invasion (T3b). BJU Int. 2008; 101: 444-9.

26. Hatcher PA, Anderson EE, Paulson DF, Carson CC, Robertson JE: Surgical management and prognosis of renal cell carcinoma invading the vena cava. J Urol. 1991; 145: 20-3; discussion 23-4.

27. Ljungberg B, Stenling R, Osterdahl B, Farrelly E, Aberg T, Roos G: Vein invasion in renal cell carcinoma: impact on metastatic behavior and survival. J Urol. 1995; 154: 1681-4

28. Manassero F, Mogorovich A, Di Paola G, Valent F, Perrone $V$, Signori S, et al.: Renal cell carcinoma with caval involvement: contemporary strategies of surgical treatment. Urol Oncol. 2011; 29: 745-50.

29. Lee CT, Katz J, Fearn PA, Russo P: Mode of presentation of renal cell carcinoma provides prognostic information. Urol Oncol. 2002; 7: 135-40.

30. Szendroi A, Tabák A, Riesz P, Szucs M, Nyírády P, Majoros $A$, et al.: Clinical symptoms related to renal cell carcinoma are independent prognostic factors for intraoperative complications and overall survival. Int Urol Nephrol. 2009; 41: 835-42.
Correspondence address: Dr. Cheol Kwak Department of Urology, Seoul National University College of Medicine 28, Yongon-Dong, Chongno-Ku, Seoul, 110-744,Korea

Fax: + $822742-4665$ E-mail: mdrafael@snu.ac.kr 